\title{
Preparation of functionalized poly(caprolactone diol)/ castor oils blends to be applied as photocrosslinkable tissue adhesives
}

\author{
Teresa Cernadas $^{1}$ | Stacy Morgado ${ }^{1}$ | Patrícia Alves ${ }^{1}$ | \\ Filipa A. M. M. Gonçalves ${ }^{1}$ | Tiago R. Correia ${ }^{2}$ | Ilídio J. Correia ${ }^{1,2}$ | \\ Paula Ferreira $^{1}$ ()
}

${ }^{1}$ CIEPQPF, Department of Chemical Engineering, University of Coimbra, Coimbra, Portugal

${ }^{2}$ CICS-UBI, Health Sciences Research Center, University of Beira Interior,

Covilhã, Portugal

\section{Correspondence}

Paula Ferreira, CIEPQPF, Department of Chemical Engineering, University of Coimbra, P-3030 790 Coimbra, Portugal. Email: pferreira@eq.uc.pt

Funding information

Fundação para a Ciência e a Tecnologia, Grant/Award Numbers: IF/01432/2015, POCI-01-0145-FEDER-007491, Project UID/Multi/00709/2013, CENTRO01-0145-FEDER-028989

\begin{abstract}
Polycaprolactone (PCL) and PCL-based materials are widely applied in the biomedical field, however, their slow biodegradation profile makes them more suitable to be used in hard tissues, where healing requires longer periods of time. In order to adjust their properties to suit for soft tissues applications, PCL can be blended with other biodegradable materials in order to tune its degradation rate. Herein, polymeric blends of PCL and castor oil (CO) were prepared after their chemical modification with 2-isocyanatoethylmethacrylate (IEMA) in order to be applied as photocrosslinkable tissue adhesives. These functionalized macromers were chemically characterized and used to prepare polymeric blends (PCL-IEMA/CO-IEMA) with variable mass proportions. A biocompatible photoinitiator (Irgacure 2959) was added to these macromers blends which were then irradiated under UV light. The feasibility of the prepared materials as tissue adhesives was evaluated by assessment of their chemical/physical properties as well as their interaction with blood. Moreover, their cytotoxic profile was also evaluated through in vitro studies using human dermal fibroblasts as model cells.
\end{abstract}

\section{K E Y W O R D S}

bioadhesive, functionalization, photocrosslinking, polymeric blend

\section{1 | INTRODUCTION}

Surgical adhesives are medical devices of indisputable value that are aimed for the treatment and regeneration of biological tissues, since they are able to hold both wound edges together, until the tissues present sufficient mechanical strength to properly withstand wound healing. ${ }^{[1,2]}$ Throughout several decades, intensive studies have been performed to improve the effectiveness of surgical adhesives, in different tissues and application conditions. Recent progresses made them revolutionary surgical devices, given their ease and ready-to-apply features, reduction of induced trauma in the surrounding tissues, greater comfort offered to the patient, the ability to act as a controlled drug delivery system as well as the possibility of being biodegradable and therefore absorbed by the organism. ${ }^{[1]}$

Nowadays, there are several commercially available bioadhesives classified as natural or biological (e.g., collagen adhesives, ${ }^{[3,4]}$ fibrin glues, ${ }^{[5,6]}$ chitosan $^{[7,8]}$ ), synthetic and semisynthetic (cyanoacrylates, ${ }^{[9,10]}$ gelatinresorcinol-formaldehyde ${ }^{[11]}$ ) and biomimetics (marine 
mussel extracts $\left.{ }^{[12]}\right)$. However, most of these adhesives still present several limitations in their application, namely the release of toxic byproducts, inadequate mechanical properties, risk of transmitted blood diseases, risk of infections, delayed application, need of further removal, and relatively slow degradation.

To overcome such drawbacks, other options have been continuously explored, and among synthetic materials, urethane-based tissue adhesives are considered quite promising. ${ }^{[1,13,14]}$ These materials are good contenders due to the possibility of being biocompatible and if synthesized in the form of prepolymers, have the ability to react with amino groups of the proteins existent in the living tissues. This reaction results in the formation of urea linkages and on the promotion of adhesion since these covalent bonds will hold the tissue together ${ }^{[15]}$ Moreover, urethane-based adhesives present other advantage like the possibility of being biodegradable if they are synthesized with natural compounds, for example, castor oil (CO). CO is an aliphatic carboxylic acid with an 18-carbon chain, having a double bond between carbon 9 and 10 and a hydroxyl group on the carbon 12. This combination of hydroxyl group and unsaturation occurs exclusively in the castor oil molecule. ${ }^{[15]}$ Considering the medical and pharmaceutical fields, $\mathrm{CO}$ is mainly used as a laxative and as an additive in skin moisturizers, ${ }^{[16]}$ contraceptive gels, herbal preparations for labour stimulation ${ }^{[17]}$ and drug delivery systems. ${ }^{[18]}$ Moreover, CO-based polyurethane prepolymers have also been previously developed as potential bioadhesives. ${ }^{[15]}$ However, despite the good adhesion results obtained with these materials, as well as with other urethane prepolymers, ${ }^{[19-22]}$ the registered curing times were too long to face surgical demands.

A possible solution to overcome this limitation relies on the use of biodegradable, biocompatible, and photocrosslinkable polymers. Photocrosslinkable polymers have been increasingly seen as an attractive strategy in the biomedical field, since they can be produced in situ, that is, the exposure of the polymers to an UV irradiation source will result in stable polymeric matrices, in a short period of time. Further, it is possible to tailor the properties of the adhesives (e.g., mechanical strength, hydrophilicity, and porosity) through the control of some parameters, such as polymer formulation, type and amount of photoinitiator, beam wavelength, and irradiation time. ${ }^{[23-26]}$

The photopolymerization and photocrosslinkage of polymers intending the preparation of tissue adhesives has been largely developed over the years. ${ }^{[7,27,28]}$ As an example, Ferreira and coworkers developed a UV-curable biodegradable bioadhesives polycaprolactone (PCL) based. ${ }^{[27]}$ PCL is a semicrystalline linear biodegradable aliphatic polyester already approved by the US Food and Drug Administration $^{[29]}$ and that has been used in several medical applications such as drug delivery systems, ${ }^{[30]}$ resorbable sutures ${ }^{[31]}$ and as a material for tissue regeneration. ${ }^{[32]}$ Its structure presents several aliphatic ester linkages susceptible to hydrolysis and its products of degradation are either metabolized by being included in the tricarboxylic acid cycle or eliminated by renal secretion. ${ }^{[21,33]}$ Within this study, a PCL-based macromer was developed by functionalization with 2-isocyanatoethylmethacrylate (IEMA) which was further photocrosslinked via UV irradiation, using Irgacure 2959 (Ir2959) as the photoinitiating agent. ${ }^{[34]}$ This chemical functionalization with an acrylate based monomer allowed decreasing curing times in order to match them with surgical demands. Still, PCL presents a slow degradation rate and a possible way of tuning its degradation rate is by blending it with other biodegradable materials. Therefore, the aim of this work was the preparation of blends of functionalized PCL and $\mathrm{CO}$ and their following characterization in order to establish their suitability as photocrosslinkable bioadhesives. Three different stoichiometric proportions were tested using the biocompatible photoinitiator Ir2959. ${ }^{[34]}$ The chemical/ physical and thermal properties of the final materials were assessed by ${ }^{1} \mathrm{H}$ NMR, water sorption evaluation, surface energy determination, and hydrolytic degradation. Their adhesive capacity was also assessed by in vitro tests with gelatine sheets and their haemolytic and thrombogenic character were also determined as well as their cytotoxicity in human fibroblasts culture.

\section{2 | EXPERIMENTAL SECTION}

\section{1 | Materials}

Hydroxyl end functionalized PCL diol ( $\mathrm{Mn} \approx 530)$, diethyl ether (99\%), formamide (99\%), diiodomethane (99\%), ethylene glycol (99.8\%), potassium ferrocyanide (99\%), formaldehyde (37\%, stabilized with methanol), nonionic surfactant Triton X-100, Dulbecco's modified Eagle's medium (DMEM-F12), gentamicin, phosphate-buffered saline tablets (PBS), streptomycin, and trypsin were purchased from Sigma-Aldrich (Sintra, Portugal). Castor oil $(\mathrm{Mn} \approx 928.5)$ was obtained from ACROS Organics. The functional monomer IEMA (98\%) was acquired from TCI (Belgium). Photoinitiator 2-hydroxy-1-[4-(2-hydroxyethoxy) phenyl]-2-methyl-1-propanone, under the trade name of Irgacure 2959 (97-99\%), was kindly provided by BASF (Germany) and used without purification. Potassium dihydrogen phosphate (99.5\%) and calcium chloride (99.5\%) were obtained from CHEM-LAB.

Anticoagulated rabbit blood (ACD blood), used in the haemocompatibility tests, was bought from PROBIOLÓGICA (Biologic Products Company) (Lisbon, Portugal) and used in the same day it was received. 
Normal adult human dermal fibroblasts (NHDF) were obtained from PromoCell (Labclinics, SA; Barcelona, Spain) and used in cytotoxicity experiments.

3-(4,5-Dimethylthiazol-2-yl)-2,5-diphenyltetrazolium bromide (MTT) was purchased from Alfa Aesar (Ward Hill, USA). Fetal bovine serum (FBS) was bought from Biochrom AG (Berlin, Germany).

\section{$2.2 \mid$ Methods}

\subsection{1 | Synthesis of the macromers}

Macromers containing urethane groups were synthesized by modification of hydroxyl end functionalized PCL or CO with IEMA in distinct glass flasks. The ratio of NCO: OH groups used was 2:1 in the case of PCL and of 3:1 in the case of CO. The chosen solvent was diethyl ether due to its high volatility.

The reactions were performed by stirring the two components (PCL/IEMA or CO/IEMA) in conventional two neck round-bottomed glass flasks, in the absence of air (under a nitrogen atmosphere), and refluxing the solvent using a long condenser with a drying tube filled with calcium chloride to maintain reflux and avoid humidity. The flasks were placed in a water bath at the temperature of $40^{\circ} \mathrm{C}$.

The obtained functionalized macromers (PCL-IEMA and CO-IEMA) exhibited low viscosity and transparent appearance and were properly stored.

\subsection{2 | Preparation of the blends and photocrosslinking reaction}

Polymeric blends were prepared from the previously obtained macromers by mixing them in different proportions: $90 \%$ PCL-IEMA with 10\% CO-IEMA (PCL90/CO10); 75\% PCL-IEMA with 25\% CO-IEMA (PCL75/CO25), and 25\% PCL-IEMA with 75\% COIEMA (PCL25/CO75). Once homogenized, Ir2959 was added to each mixture in a percentage of $6 \%$ of the carbon double bonds moles, keeping the reaction glass flask in a dark environment until complete solubilization.

These solutions were then poured onto Petri dishes and irradiated using a Multiband UV UVGL-48 model from Mineral Light Lamp (wavelengths of 254-354 nm). Once completed the UV irradiation, transparent, uniform, and flexible films were obtained.

Gel content of the crosslinked matrices was also determined. Samples of dried films were weighted $\left(W_{\mathrm{i}}\right)$ and immersed in diethyl ether overnight in sealed containers (under stirring conditions, at room temperature). The samples were afterwards removed, dried under vacuum, and reweighted $\left(W_{\mathrm{f}}\right)$. Gel content was determined as represented in Equation (1).

$$
\text { Gel content }(\%)=\left(\frac{\mathrm{W}_{\mathrm{f}}}{\mathrm{W}_{\mathrm{i}}}\right) \times 100
$$

\section{3 | Characterization techniques}

\subsection{1 | Nuclear magnetic resonance}

The ${ }^{1} \mathrm{H}$ NMR spectra of PCL, CO, IEMA, and of the macromers were obtained on a 9.4 Tesla Spectrometer, at room temperature and using $\mathrm{CDCl}_{3}$ as solvent. Tetramethylsilane was used as the internal reference.

\subsection{2 | Water sorption capacity}

Three samples of each prepared film with an area of $4 \mathrm{~cm}^{2}$ and $1 \mathrm{~mm}$ thick were properly dried under vacuum at $60^{\circ} \mathrm{C}$ until constant weight $\left(W_{\mathrm{d}}\right)$. The dried samples were then placed in a closed container with a saturated solution of pentahydrated copper sulfate and were weighted at different times until a maximum weight was achieved $\left(W_{\mathrm{s}}\right)$. Finally, water sorption (\%) was assessed by using Equation (2).

$$
\text { Water sorption }(\%)=\left(\frac{W_{\mathrm{s}}-W_{\mathrm{d}}}{W_{\mathrm{d}}}\right) \times 100
$$

\subsection{3 | Hydrolytic degradation in phosphate buffer solution (PBS)}

Dried samples $(n=3)$ of each film (1 mm of thickness) were weighted $\left(W_{\mathrm{d}, 0}\right)$, immersed in $10 \mathrm{ml}$ of PBS $0.01 \mathrm{M}$ $\left(\mathrm{pH}\right.$ 7.4), and then incubated for 6 weeks at $37^{\circ} \mathrm{C}$. The films were afterwards removed from PBS, washed with distilled water and dried in vacuum conditions, at $60^{\circ} \mathrm{C}$, until constant weight $\left(W_{\mathrm{d}, \mathrm{t}}\right)$. The degree of degradation was calculated from the weight loss, which was determined as presented in Equation (3).

$$
\text { Weight loss }(\%)=\frac{W_{\mathrm{d}, 0}-W_{\mathrm{d}, \mathrm{t}}}{W_{\mathrm{d}, 0}} \times 100
$$

where $W_{\mathrm{d}, 0}$ and $W_{\mathrm{d}, \mathrm{t}}$ are the average samples weights before the degradation test and at time $t$, respectively. 


\subsection{4 | In vitro adhesion tests- Evaluation of the adhesive capacity}

In order to evaluate the bonding performance of the photocrosslinkable macromers, the viscous formulations containing the photoinitiator were applied between gelatine sheets (dimensions $1.5 \times 3 \mathrm{~cm}$ ). The gelatine pieces containing the adhesives formulations were overlapped (active area $1.5 \times 1 \mathrm{~cm}$ ) and then irradiated under the same conditions described for the preparation of the films obtaining a specimen with total dimensions of $1.5 \times 5 \mathrm{~cm}$. The gelatine sheets were then subjected to the "pull to break" test at room temperature using a Chatillon TCD 1000 (Lloyd Instruments, Ametek, Berwyn, PA). The pulling velocity was $20 \mathrm{~mm} / \mathrm{min}$, and the distance between the probes was established at $1 \mathrm{~cm}$. The assays were carried out at room temperature. The software program coupled to the apparatus registered the force and length variation. The tests terminated with the fracture of the gelatine sheets or their separation in case adhesion failed to occur. A gelatine sheet with no treatment $(1.5 \times 5 \mathrm{~cm})$ was also subjected to the same test in order to act as a control.

\subsection{5 | Determination of surface energy by contact angle measurement}

The surface energies of the films were determined, in order to compare their values with the ones obtained from literature for skin and blood. An OCA 20 unit from Dataphysics was used to measure the static contact angles at room temperature. ${ }^{[35]}$ All the assays were conducted on the air-facing surfaces of the films with three liquids (water, ethylene glycol formamide, and diiodomethane) using the sessile drop method. Ten measurements on several points were performed on the samples surface to determine the mean static contact angle and its standard error (SE). The surface free energies $\left(\gamma_{\mathrm{s}}\right)$ as well as their dispersive $\left(\gamma_{\mathrm{S}}^{\mathrm{D}}\right)$ and polar $\left(\gamma_{\mathrm{S}}^{\mathrm{P}}\right)$ components were assessed according to the Owens-Wendt-Rabel, and Kaelble (OWRK) method. ${ }^{[36]}$

\subsection{6 | Thermal properties}

The thermal stability of PCL, CO and the three developed adhesives was evaluated in the range of ca. $25-600^{\circ} \mathrm{C}$, in an Q500 of TA Instruments from thermal analysis, at inert atmosphere with a heating rate of $10^{\circ} \mathrm{C} / \mathrm{min}$ under dry nitrogen purge flow of $100 \mathrm{ml} / \mathrm{min}$. Differential scanning calorimetry (DSC) studies were performed within a temperature interval ranging from -80 to $100^{\circ} \mathrm{C}$, in a TA Q100 instrument at a heating rate of $10^{\circ} \mathrm{C} / \mathrm{min}$ in the temperature modulated mode, and under a nitrogen flow of $50 \mathrm{ml} / \mathrm{min}$.

\subsection{7 | Haemocompatibility analysis}

The assessment of haemocompatibility is an essential requirement for all materials intended to contact with blood. During this work, the compatibility of the prepared materials with blood was evaluated in vitro accordingly to the International Organization for Standardization (ISO) 10993-4 $4^{[37]}$ and by assessing two types of blood interaction: thrombogenicity and haemolytic potential.

\section{Thrombogenicity}

Thrombus formation on the surface of the films $(n=3)$ was evaluated using the gravimetric method of Imai and Nose. ${ }^{[38]}$ Anticoagulated rabbit blood (ACD blood) was used for this purpose and contact time between the samples and blood was established at $40 \mathrm{~min}$. The samples were previously immersed in PBS solution at $37^{\circ} \mathrm{C}$, for $24 \mathrm{hr}$. Subsequently, the PBS was removed and the ACD blood $(250 \mu \mathrm{l})$ was placed on the adhesives surface. The same amount of blood was sited over empty Petri dishes $(n=3)$, which acted as the positive control. Blood clotting tests were started with the addition of $25 \mu \mathrm{l}$ of a $0.10 \mathrm{M}$ calcium chloride solution to each sample which were posteriorly incubated at $37^{\circ} \mathrm{C}$ for $40 \mathrm{~min}$. The process was terminated by adding $5 \mathrm{ml}$ of distilled water to each sample. The resultant clots were fixed with $1 \mathrm{ml}$ of a $36 \%$ formaldehyde solution, dried at $37^{\circ} \mathrm{C}$ for $24 \mathrm{hr}$ and finally weighted. The percentage of thrombogenicity was assessed according to Equation (4).

$$
\begin{aligned}
& \text { \% Thrombogenicity } \\
& =\frac{m_{\text {clot sample }}-m_{\text {average negative control }}}{m_{\text {average positive control }}-m_{\text {average negative control }}} \times 100
\end{aligned}
$$

\section{Haemolytic potential}

The haemolysis tests were performed according to the American Society for Testing and Materials (ASTM) F 756-00 standard. ${ }^{[39]}$ Dried samples with $21 \mathrm{~cm}^{2}$ were placed in polypropylene test tubes and $7 \mathrm{ml}$ of $\mathrm{PBS}(0.01 \mathrm{M}$, $\mathrm{pH}$ 7.4) were added. After $24 \mathrm{hr}$ of incubation at $37^{\circ} \mathrm{C}$, the PBS was removed and the samples were left to dry. Then, $7 \mathrm{ml}$ of PBS and $1 \mathrm{ml}$ of diluted ACD blood $(10 \pm 1 \mathrm{mg} / \mathrm{ml})$ were added to each sample (indirect contact) as well as to three samples of the same membranes with no previous 
incubation with PBS (direct contact). Positive and negative controls were prepared by adding the same amount of ACD blood to $7 \mathrm{ml}$ of water and PBS, respectively.

The tubes were placed at $37^{\circ} \mathrm{C}$, for $3 \mathrm{hr}$, and cautiously inverted twice every $30 \mathrm{~min}$ for enhancing the contact between materials and blood. After incubation, the fluids were transferred to suitable tubes and centrifuged at 700-800g, for $15 \mathrm{~min}$. The amount of hemoglobin $(\mathrm{Hb})$ released by haemolysis was measured by optical densities (OD) of the supernatants at $540 \mathrm{~nm}$ using a spectrophotometer UV-Vis (Jasco V550). The percentages of haemolysis (HI) were calculated as described in Equation (5).

$\%$ Haemolysis $(\mathrm{HI})=\left(\frac{\mathrm{OD}_{\text {test }}-\mathrm{OD}_{\text {negative control }}}{\mathrm{OD}_{\text {positive control }}-\mathrm{OD}_{\text {negative control }}}\right) \times 100$

\subsection{8 | Evaluation of films biocompatibility}

\section{Cell culture of human fibroblasts in presence of the polymeric blends}

Cell culture in the presence of the films was assessed as previously described. ${ }^{[36,40]}$ Briefly, samples of each film were sterilized using ultraviolet radiation for $30 \mathrm{~min}$. Afterwards, normal human dermal fibroblasts adult (hFib) were seeded in the presence of the polymeric blends $\left(2 \times 10^{4}\right.$ cells/film $)$ in 96-well plates, using DMEM-F12, supplemented with FBS (10\% vol/vol), streptomycin $(100 \mu \mathrm{g} / \mathrm{ml})$, and gentamicin $(100 \mu \mathrm{g} / \mathrm{ml})$. Cell growth was monitored using an Olympus CX41 inverted light microscope (Tokyo, Japan) equipped with an Olympus SP-500 UZ digital camera.

\section{Evaluation of cell viability in the presence of the polymeric blends}

The cytotoxic profile of the produced materials was evaluated by seeding NHDF $\left(2 \times 10^{4}\right.$ cells/well $)$ in the presence of the materials, in 96-well plates, with $100 \mu \mathrm{l}$ of DMEM-F12 and then incubated at $37^{\circ} \mathrm{C}$, in a $5 \% \mathrm{CO}_{2}$ humidified atmosphere. After 24 and $72 \mathrm{hr}$ of incubation, cell viability was assessed by performing an MTT assay. To accomplish that $50 \mu \mathrm{l}$ of MTT $(5 \mathrm{mg} / \mathrm{ml}$ PBS) was added to each sample and then was incubated for $4 \mathrm{hr}$, at $37^{\circ} \mathrm{C}$, in a $5 \% \mathrm{CO}_{2}$ atmosphere. After that, the medium was removed and cells were treated with $150 \mu$ l of DMSO $(0.04 \mathrm{~N})$ for $30 \mathrm{~min}$. The absorbance of each well was determined at $570 \mathrm{~nm}$ using a microplate reader (Biorad xMark microplate spectrophotometer). Wells containing cells in the culture medium without materials were used as negative control $(\mathrm{K}-)$. EtOH $96 \%$ was added to wells containing cells to be used as a positive control $(\mathrm{K}+)^{[35]}$
Statistical analysis of the obtained results was performed using one-way ANOVA with the Newman-Keuls post hoc test.

\subsection{9 | Scanning electron microscopy analysis}

To characterize the cellular attachment on films surface, scanning electron microscopy (SEM) analysis was performed. Briefly, samples were washed with PBS at room temperature and fixed overnight with $2.5 \%(\mathrm{v} / \mathrm{v})$ glutaraldehyde. Then, films were frozen, freeze-dried for $3 \mathrm{hr}$, and finally mounted onto aluminium stubs with double adhesive tape and sputter-coated with gold using a Quorum Q150R ES sputter coater. SEM images were acquired with an acceleration voltage of $20 \mathrm{kV}$ at different magnifications in a Hitachi S-3400N Scanning Electron Microscope. ${ }^{[36,41]}$

\section{3 | RESULTS AND DISCUSSION}

\section{1 | Synthesis}

The preparation of the crosslinked adhesives was conducted through two distinct steps, being the first one the synthesis of prepolymers based on PCL and CO were functionalized with IEMA, an isocyanate-functional monomer containing carbon double bonds. The ratio of NCO:OH groups used was 2:1 and 3:1, for PCL-IEMA and CO-IEMA, respectively. This reaction between the isocyanate groups of IEMA and the $\mathrm{OH}$ groups of PCL and $\mathrm{CO}$, lead to the formation of urethane groups, which can promote the restoration of living tissues. ${ }^{[21]}$ The synthesis of the macromers is summarized in Figure 1.

Afterwards, the macromers were mixed with each other, leading to the following proportions: $90 \%$ PCL-IEMA with 10\% CO-IEMA (PCL90/CO10), 75\% PCL-IEMA with 25\% CO-IEMA (PCL75/CO25), and 25\% PCL-IEMA with 75\% CO-IEMA (PCL25/CO75). Finally, the polymeric blends were photocrosslinked under UV irradiation using Ir2959, in a percentage of $6 \%$ of the carbon double bonds moles. Irradiation times varied with composition and were determined to be $3 \mathrm{~min}$. For PCL90/CO10 (gel content of 92\%), 6 min. For PCL75/ CO25 (gel content of $89 \%$ ) and 8 min. For PCL25/CO75 (gel content of 78\%), showing that a higher amount of PCL-IEMA in the composition of the macromers leads to an increased curing efficiency.

The films obtained from each composition were then physical/chemically and biologically characterized. 
(a)

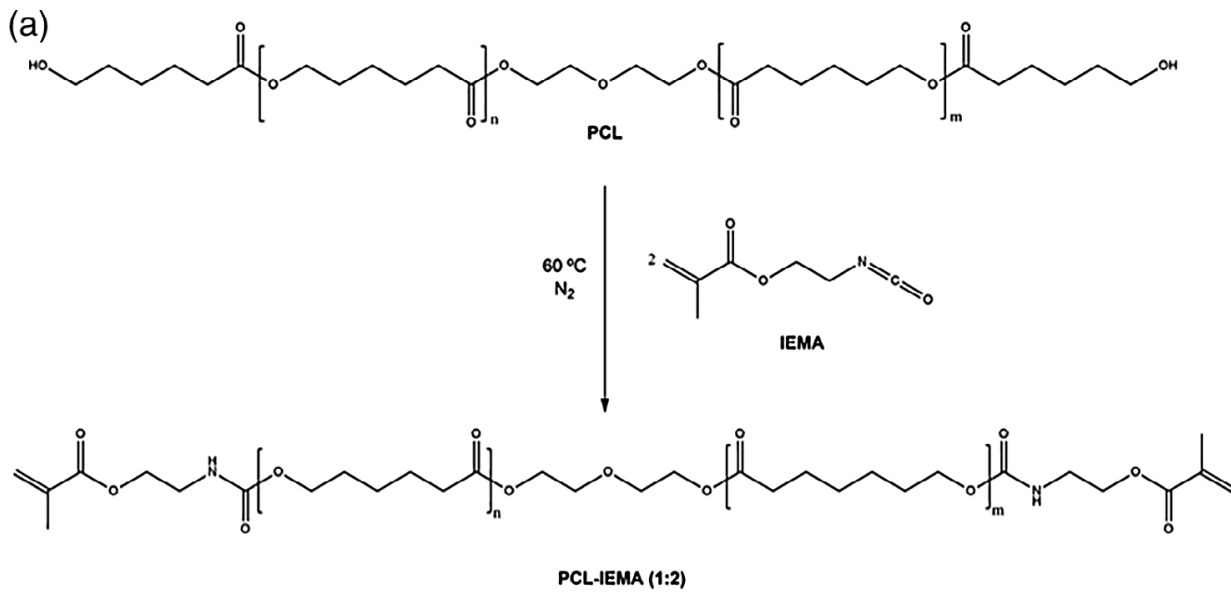

(b)

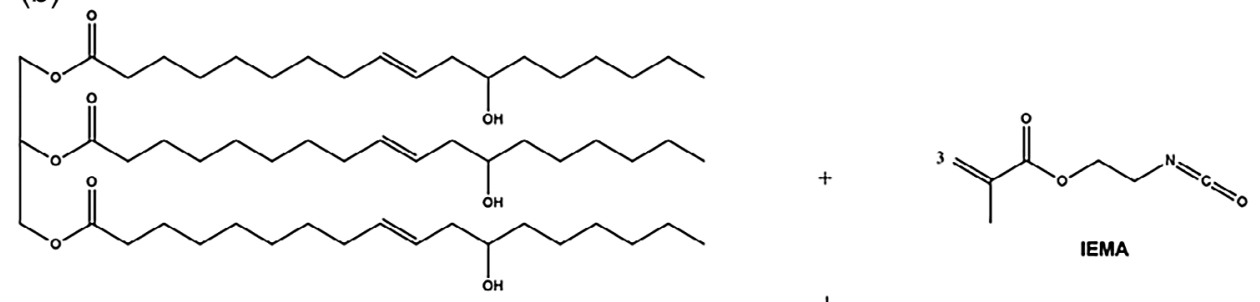

FIGURE 1 Schematic representation of the macromers synthesis (a). Synthesis of PCLIEMA (b). Preparation of the CO-IEMA

co

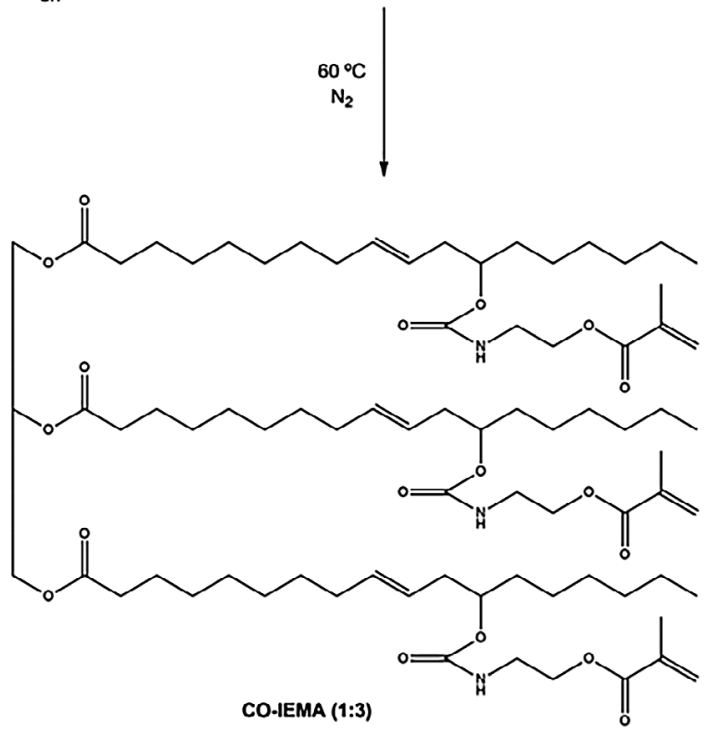

\section{2 | ${ }^{1} \mathrm{H}$ NMR of functionalized macromers}

Functionalized macromers (PCL-IEMA and CO-IEMA) were synthesized by reaction between $\mathrm{OH}$ groups from PCL and $\mathrm{CO}$ with the isocyanate groups from IEMA attaining urethane linkages. ${ }^{1} \mathrm{H}$ NMR technique was used to characterize PCL, CO, IEMA, and the synthesized macromers, shown in Figures 2 and 3. The spectrum of IEMA in Figures 2 and 3 (2) shows the characteristic isocyanate peak at $3.6 \mathrm{ppm}(\mathrm{i})$, the olefinic protons $(-\mathrm{HC}=\mathrm{C}-$ ) from 5.5 to $6.5 \mathrm{ppm}(\mathrm{k})$ and the $\mathrm{CH}_{3}$ of the terminal group at $1.9 \mathrm{ppm}$. The PCL spectrum in Figure 2 (1) shows a peaks at 3.7 assigned respectively to the $\mathrm{OCH}_{2}-$ and (a) 1.4, (b) 1.6 , (c) 2.3 , and (f) $4.1 \mathrm{ppm}$ ascribed to $-\mathrm{CH}_{2} \mathrm{CH}_{2}-$ protons in the backbone chain of PCL. ${ }^{[42]}$ Castor oil spectrum (Figure 3 (1)) shows the methine proton of the glycerol at (c) $5.4 \mathrm{ppm}$, and the cis-double bonds at (d) 5.6 ppm. ${ }^{[43]}$ The ${ }^{1} \mathrm{H}$ NMR spectrum of obtained macromers (3) both exhibited three new resonances: (k) from 5.5 to $6.5 \mathrm{ppm}$, assigned to the olefinic protons $(-H \mathrm{C}=\mathrm{C}-)$; (i) at $3.6 \mathrm{ppm}$ attributed to the protons of $\mathrm{CH}_{2}$ groups linked to the $\mathrm{NH}$ of the urethane function ${ }^{[36]}$ and (h) $1.9 \mathrm{ppm}$ ascribed to the $\mathrm{CH}_{3}$ of the terminal groups of IEMA linked to the macromers, ${ }^{[4]}$ confirming the synthesis. 
F I G U RE $2 \quad{ }^{1} \mathrm{H}$ NMR spectra of PCL-IEMA. The numbered signals correspond to the protons assigned to the displayed structure
(1)

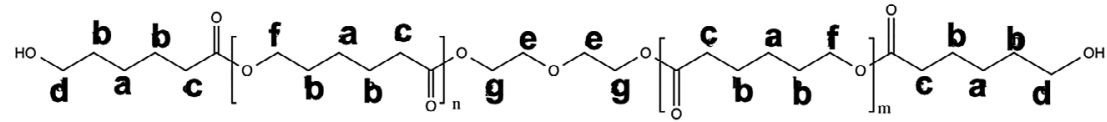

(2)

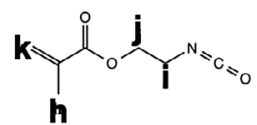

(3)
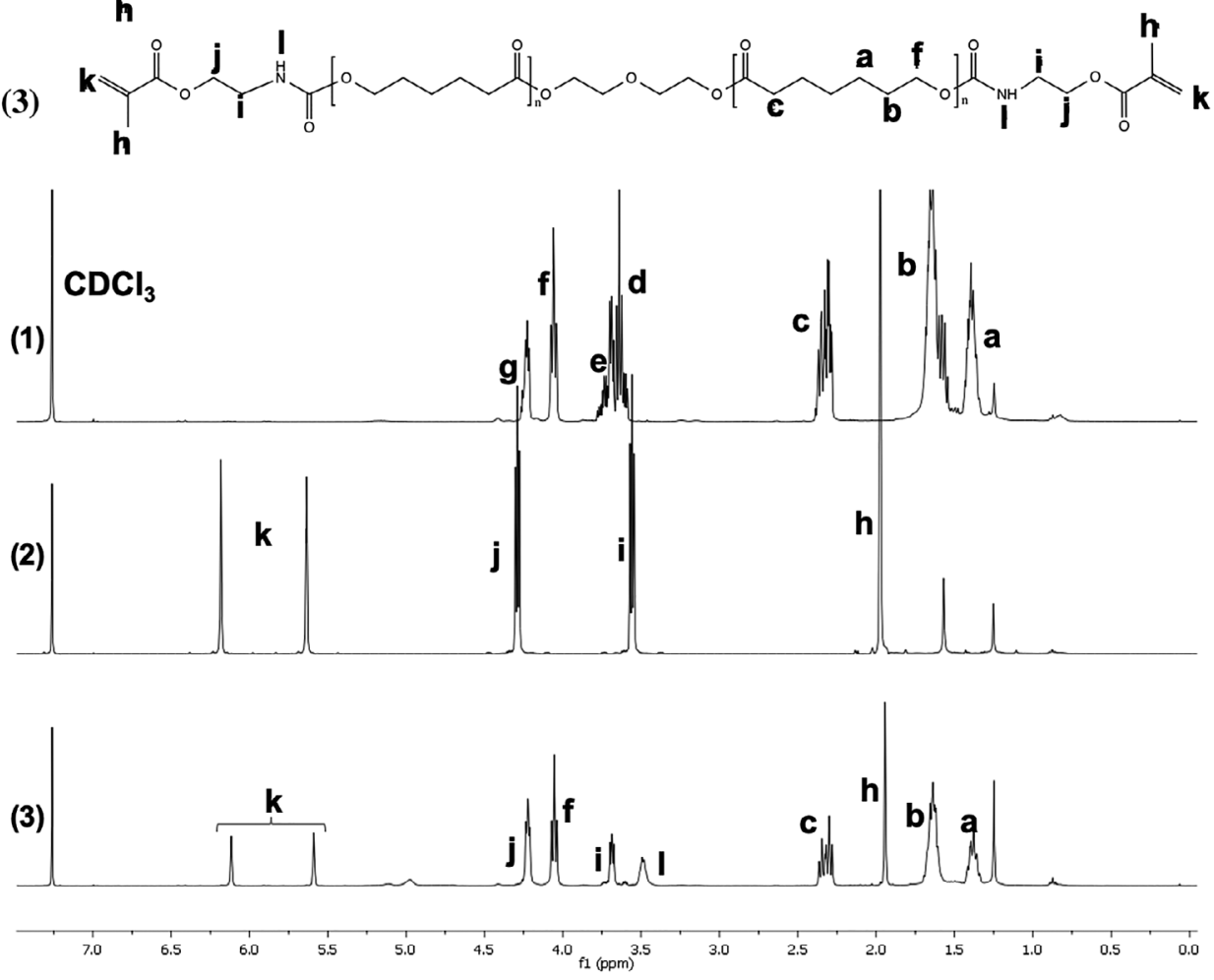

\subsection{Water sorption capacity}

Water sorption, and consequent materials' volume increase (swelling), is a fundamental parameter to be assessed in order to determine its suitability as a tissue/surgical adhesive. These adhesives are designed to assist the healing processes of damaged tissues, promoting their restructuring, reconstitution, and treatment. ${ }^{[40]}$ Therefore, high swelling degrees (above 20\%), may impair these stages of healing by keeping the wound edges apart and by damaging surrounding tissues due to excessive compression of vascular structures or to inflammatory responses. ${ }^{[40]}$

Water sorption capacity was determined for three samples of each prepared film (Figure 4). Since PCL is a mildly hydrophobic material ${ }^{[45]}$ medium water sorption value for PCL90/CO10 is $6.7 \pm 0.2 \%$. Moreover, results show that increasing the amount of $\mathrm{CO}$ in the composition of the polymeric blends decreases the hydrophilicity of the final material.

This fact is due to the highly hydrophobic nature of the castor oil molecule associated to its structure composed of long carbon chains. ${ }^{[46]}$ Therefore, the most visible effect in swelling was registered to the material with $75 \%$ of CO-IEMA (PCL25/CO75) with a medium value of water sorption of $4.7 \pm 0.4 \%$. These results are consistent with the ones obtained during surface energy assessment, since this was the sample with the lower polar component.

Despite the observed differences, all the materials exhibited a moderate water uptake in agreement with the initial requirements which will contribute to their biocompatibility.

\section{4 | Hydrolytic degradation in phosphate buffer solution (PBS)}

The degradation rate by hydrolysis of the crosslinked adhesives is presented in Figure 5 and was measured as the mass loss over time of exposure to the buffer solution, at $37^{\circ} \mathrm{C}$. According to Figure 5, the copolymer presenting a higher content of CO, PCL25/CO75, also exhibited the highest value of weigh loss of $9.5 \pm 0.8 \%$, while the copolymers PCL75/CO25 and PCL90/CO10 presented a weight loss of $6.8 \pm 0.4 \%$ and $6.3 \pm 0.9 \%$, respectively. Therefore, increasing the amount of $\mathrm{CO}$ in the copolymer formulations resulted in an increase of the weight loss, which corroborates the gel content of the materials, in which 


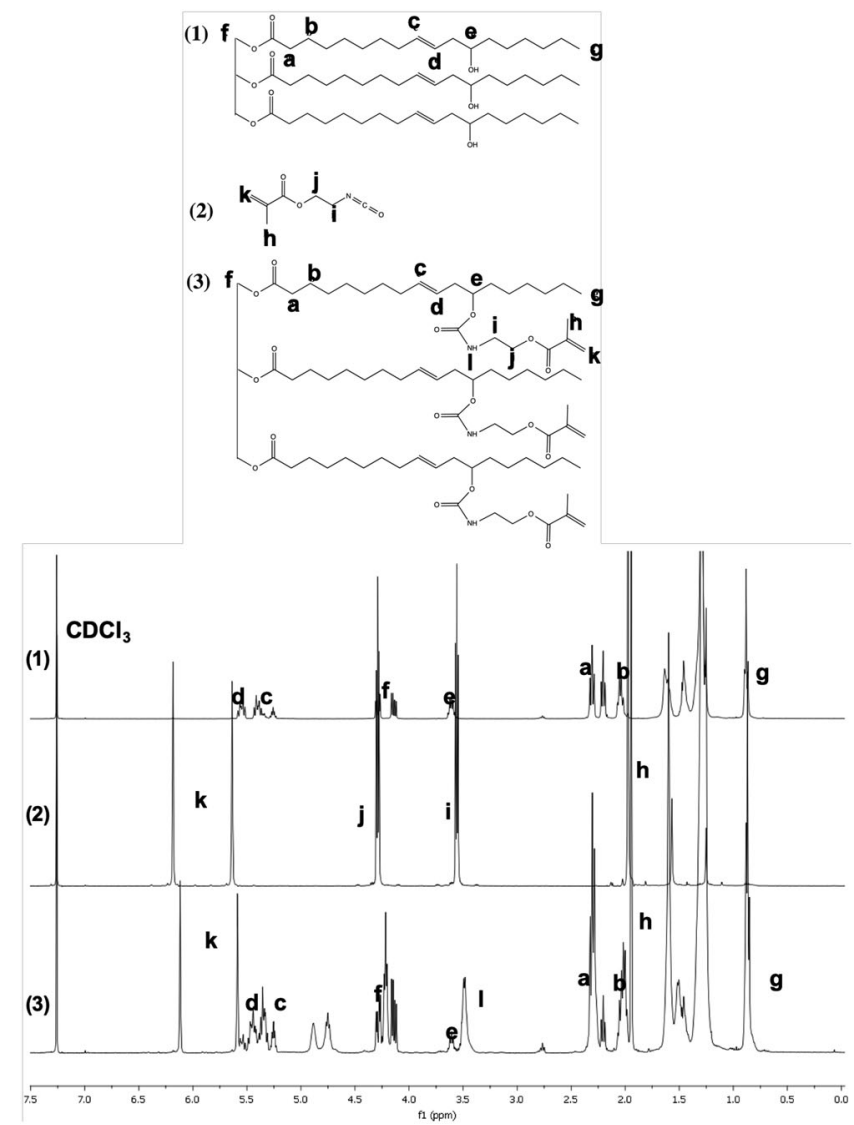

F I G U R E $3 \quad{ }^{1} \mathrm{H}$ NMR spectra of CO-IEMA. The numbered signals correspond to the protons assigned to the displayed structure

copolymer PCL90/CO10 presented the highest degree of crosslinking.

\section{5 | In vitro adhesion tests-Evaluation of the adhesive capacity}

In order to evaluate the binding capacity of the copolymers, the different formulations were placed between

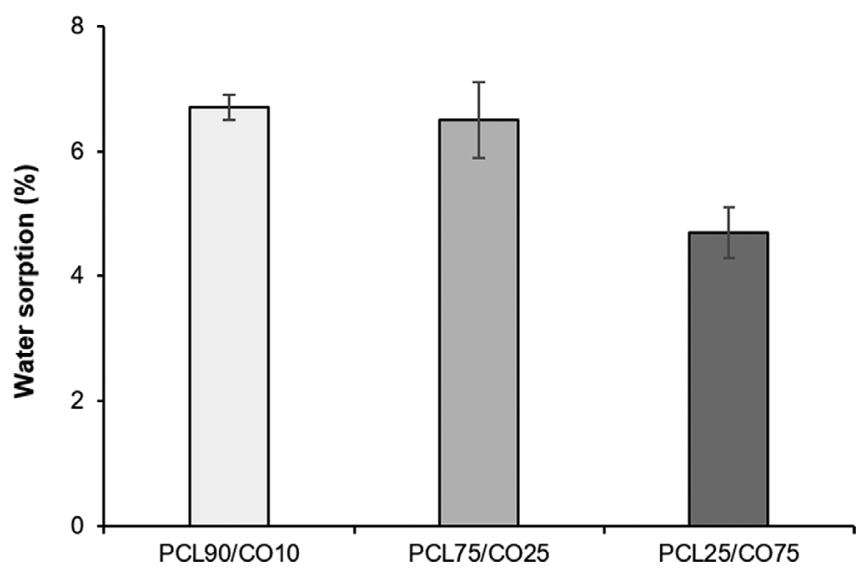

F I G U R E 4 Swelling behavior of the adhesives after 6 weeks

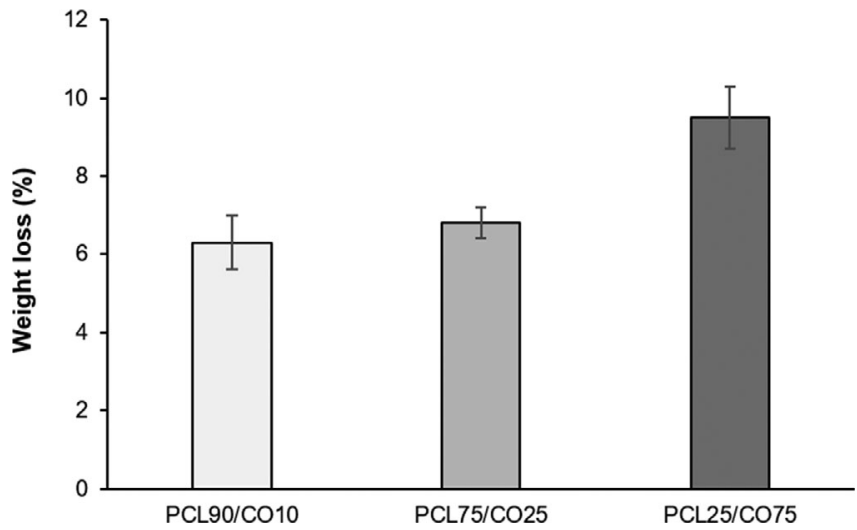

F I G U RE 5 Hydrolytic degradation profile of the adhesives

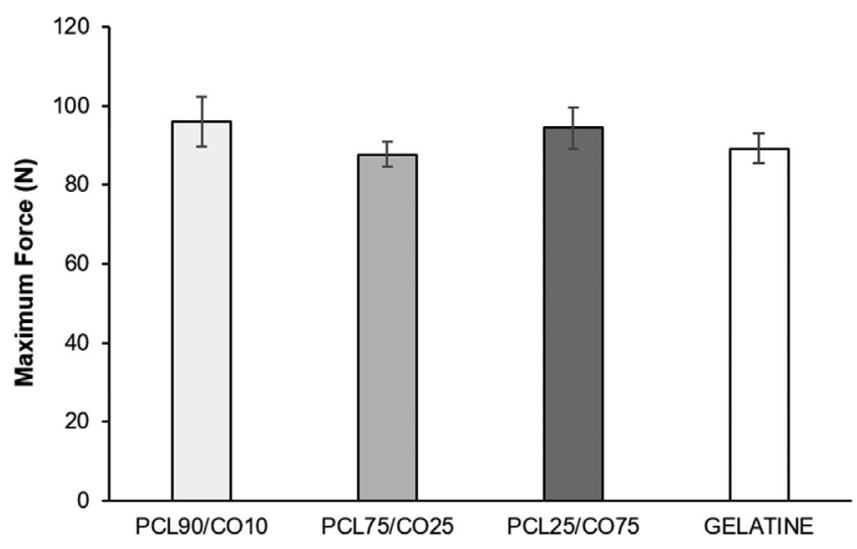

F I G U RE 6 Adhesion capacities of the different copolymers and gelatin sheets (acting as a control)

two gelatine sheets which were then irradiated with UV light during the preestablished period of time for each polymeric blend. The choice of the substrate is justified by the high presence of amino groups, therefore mimicking the living tissues. ${ }^{[15]}$ The assay was concluded either by the gelatine sheets fracture or by their separation. The maximum force $(\mathrm{N})$ obtained for the copolymers and gelatine sheets are displayed in Figure 6. According with Figure 6. the copolymers revealed good adhesion to the substrate with values of force higher than the substrate (89.2 $\mathrm{N} \pm 3.7$ ). Copolymer PCL25/CO75 was the only adhesive presenting a maximum force slightly lower than the gelatine sheet with a maximum force of $87.7 \mathrm{~N} \pm 3.2$. Despite this value, no detachment of the gelatine sheets was observed in any of the assays.

\section{6 | Determination of surface energy by contact angle measurement}

To evaluate the interaction between the copolymers and liquids, surface energy of the materials was determined. This is an important parameter since it allows inferring 
about polymer's wettability, the interaction between polymer-substrate and biocompatibility. ${ }^{[4]}$

The values were assessed by determining the static contact angle using three liquids: water, ethylene glycol, and diiodomethane. Gelatine sheet surface tension was also determined and then compared with those exhibited by the skin and blood. Skin's surface energy varies between 38 and $56 \mathrm{mN} / \mathrm{m},{ }^{[48]}$ since it is affected by relative humidity and temperature of the skin. For blood, the

T A B L E 1 Surface energies/superficial tensions ( $\mathrm{mN} / \mathrm{m})$ and their dispersive $\left(\gamma_{\mathrm{S}}^{\mathrm{D}}\right)$ and polar $\left(\gamma_{\mathrm{S}}^{\mathrm{P}}\right)$ components

\begin{tabular}{llll} 
& \multicolumn{3}{l}{$\begin{array}{l}\text { Surface energies and surface } \\
\text { tensions }(\mathbf{m N} / \mathbf{m})\end{array}$} \\
\cline { 2 - 4 } Substrate & $\gamma_{\mathrm{S}}$ & $\gamma_{\mathrm{S}}^{\mathrm{D}}$ & $\gamma_{\mathrm{S}}^{\mathrm{P}}$ \\
\hline Gelatine & $44.1 \pm 2.3$ & $5.3 \pm 0.6$ & $38.9 \pm 2.2$ \\
\hline Skin & 43.7 & 35.7 & 8.0 \\
\hline Blood & 47.5 & 11.2 & 36.3 \\
\hline PCL90/CO10 & $31.2 \pm 2.4$ & $2.4 \pm 0.6$ & $28.8 \pm 2.4$ \\
\hline PCL75/CO25 & $29.2 \pm 2.6$ & $2.0 \pm 0.5$ & $27.3 \pm 2.5$ \\
\hline PCL25/CO75 & $31.1 \pm 2.8$ & $7.4 \pm 1.1$ & $23.7 \pm 2.6$ \\
\hline
\end{tabular}

(a)

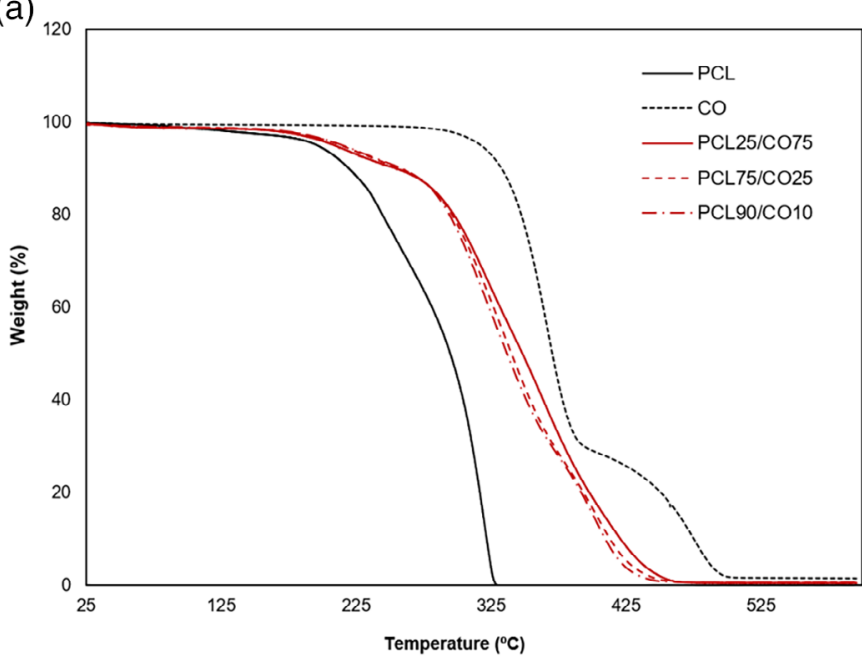

surface tension reported is $47.5 \mathrm{mN} / \mathrm{m} \cdot{ }^{[49,50]}$ The dispersive $\gamma_{\mathrm{S}}^{\mathrm{D}}$ and polar $\gamma_{\mathrm{S}}^{\mathrm{P}}$ parts of the surface energy, determined by the Owens-Wendt-Rabel and Kaelble model, were obtained for the adhesives and the results are summarized in Table 1.

According to Table 1, the surface energies of the materials are lower than the obtained for the gelatine sheet $(44.1 \pm 2.3 \mathrm{mN} / \mathrm{m})$ and the ones documented for skin and blood, which is a good indicator of the viability of the materials as adhesives since the surface energy of the adhesive is lower than that of any of these adherent. ${ }^{[48]}$ Also, the polar components are significantly higher in comparison with the dispersive part, meaning that the adhesion forces are predominant over the cohesive forces. Comparing the three adhesives, no significant changes occur with the increase of $\mathrm{CO}$ in the formulations.

\section{7 | Thermal properties}

The thermal stability of PCL, CO, and the polymeric blends was also evaluated by TGA under nitrogen atmosphere (Figure 7 and Table 2).

(b)

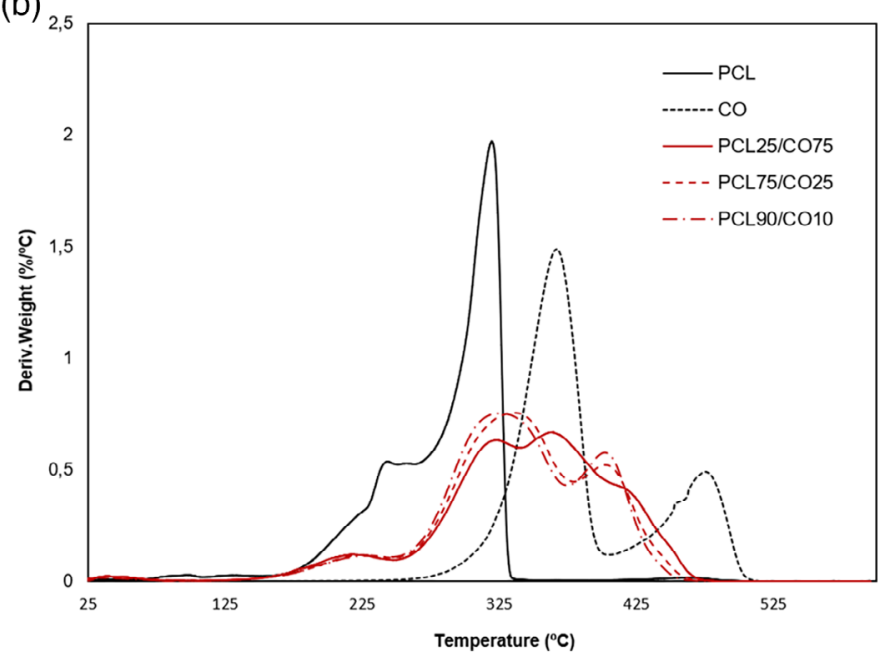

F I G U RE 7 TGA thermograms (a) and derivate thermogravimetric curves of the reactants and final adhesives (b) [Color figure can be viewed at wileyonlinelibrary.com]

T A B L E 2 Thermal properties of the developed adhesives, degradation temperature $\left(T_{x \%}\right)$, onset temperature $\left(T_{\mathrm{d}}\right)$, and $T_{\mathrm{g}}($ glass transition temperature)

\begin{tabular}{|c|c|c|c|c|c|c|}
\hline Sample & $T_{5 \%}\left({ }^{\circ} \mathrm{C}\right)$ & $T_{10 \%}\left({ }^{\circ} \mathrm{C}\right)$ & \multicolumn{3}{|l|}{$T_{\mathrm{d}}$} & $T_{\mathrm{g}}\left({ }^{\circ} \mathrm{C}\right)$ \\
\hline PCL & 195.82 & 219.34 & 243.81 & 319.6 & - & - \\
\hline $\mathrm{CO}$ & 317.15 & 332.81 & 367.39 & 475.49 & - & - \\
\hline PCL90/CO10 & 214.40 & 259.09 & 223.72 & 325.24 & 402.38 & -75.8 \\
\hline
\end{tabular}


The results obtained through TGA analyses showed that thermal degradation of PCL occurred in two stages at 243.81 and $319.60^{\circ} \mathrm{C}$ suggesting a double degradation mechanism that occurs at different temperatures. These results were previously obtained and explained by other authors. ${ }^{[51]}$ While the first degradation step results in water, $\mathrm{CO}_{2}$, and carboxylic acid formation, the second one leads to the depolymerization of the PCL chains resulting in the formation of $\varepsilon$-caprolactone.

The registered thermogram for castor oil also displays a two-stage decomposition mechanism. The first $T_{\mathrm{d}}$ at $367.39^{\circ} \mathrm{C}$ is attributed to the thermal degradation of the ester bonds while the second one at $475.49^{\circ} \mathrm{C}$ corresponds to the breaking of high energy double and single bonds of the remaining fatty acids from castor oil. ${ }^{[52]}$

Considering the polymeric blends, three decomposition stages were observed in the thermograms of PCL90/ CO10 and PCL75/CO25 as confirmed in the correspondent derivative TGA curves, which showed three maximum peaks. The first thermal decomposition was registered at around $220^{\circ} \mathrm{C}$ and is related to the degradation of the urethane bonds which results in the formation of carbon dioxide, carbon monoxide, amines, and aldehydes. ${ }^{[52]}$ The second decomposition, around $330^{\circ} \mathrm{C}$, is attributed to the degradation of the ester bonds in the soft segments of the urethanes. The value of this degradation temperature is higher than for unmodified PCL due to presence of urethane hard segments, which allows the establishment of hydrogen bonds between urethanes $\mathrm{NH}$ and $\mathrm{CO} / \mathrm{C}=\mathrm{O}$ groups. ${ }^{[53]}$ In these blends, only one peak was observed for this second stage of decomposition indicating that the miscibility of the blends. ${ }^{[54]}$ Finally, a third stage of thermal degradation was registered at $402^{\circ} \mathrm{C}$ attributed to the decomposition of the bonds with higher energy such as $\mathrm{C}=\mathrm{O}, \mathrm{C}=\mathrm{C}, \mathrm{C}-\mathrm{O}$, and $\mathrm{C}-\mathrm{H}$ bonds. ${ }^{[52]}$

Considering the PCL25/CO75 blend, a significant difference was observed at the second stage of decomposition,

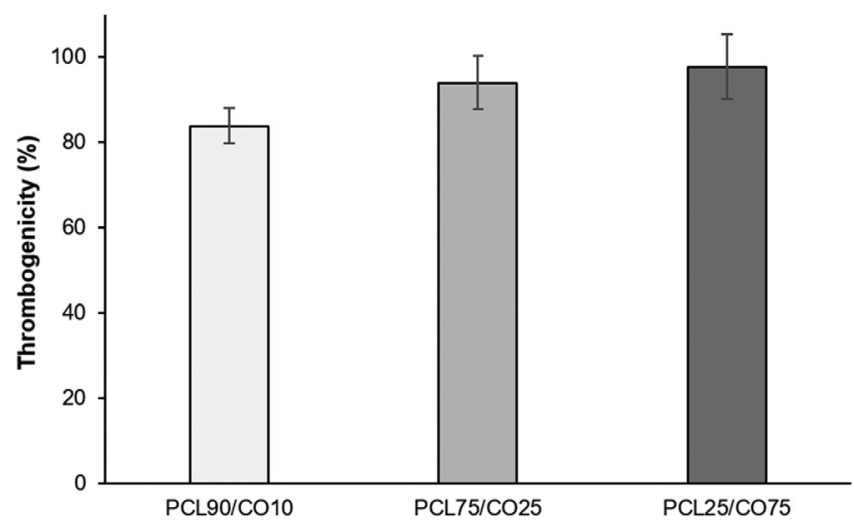

F I G URE 8 Weight of thrombus formed after $45 \mathrm{~min}$ of contact with blood which in fact presented itself as two separated stages at 323.78 and $363.33^{\circ} \mathrm{C}$. When observing the thermograms of PCL and CO, it is possible to verify that these values are close to those of the original polymers, and therefore indicate a degree of immiscibility of the blends at this proportion. ${ }^{[54]}$ All the other decomposition stages are the same as previously described, including the degradation of the urethane linkages and the final decomposition stage.

The $T_{\mathrm{g}}$ values were determined by DSC and are presented in Table 2. All the values were registered at low temperatures, around $-75^{\circ} \mathrm{C}$. This means that the polymer chains have high mobility and therefore high flexibility at physiological temperature. Also, no significant differences are detected between the three developed adhesives.

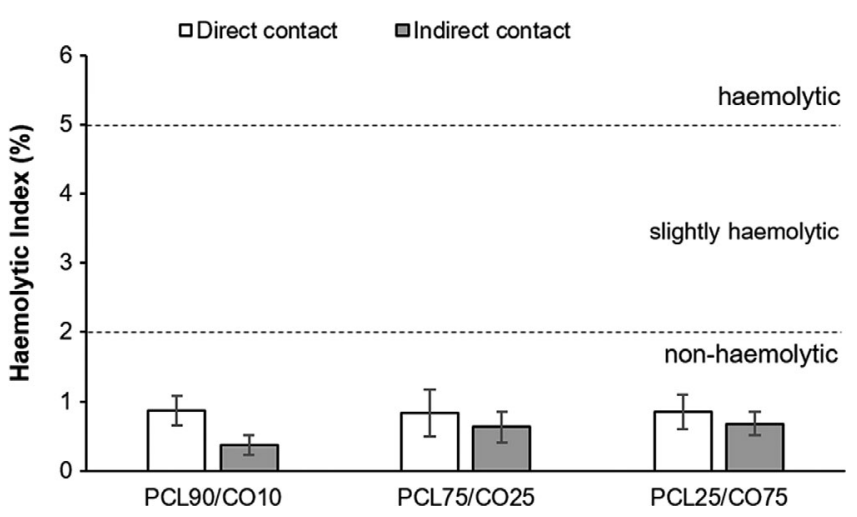

FI G URE 9 Values of haemolysis of the three adhesives

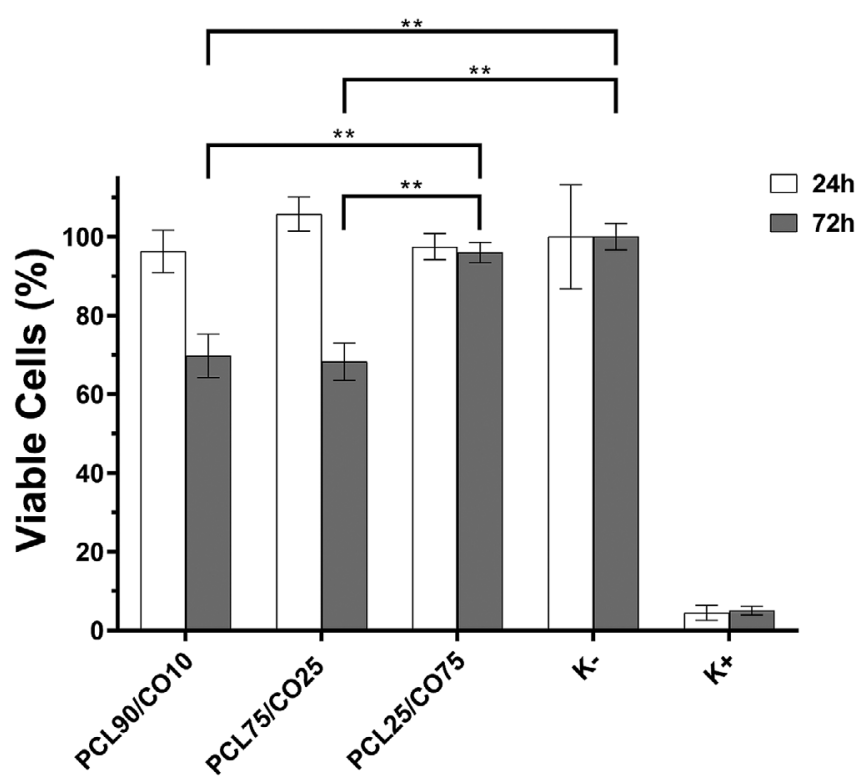

F I G U RE 10 Characterization of cell viability when cultured in contact with the different material blends after 24 and $72 \mathrm{hr}$; live cells $(\mathrm{K}-)$; dead cells $(\mathrm{K}+)$. Each result represents the mean $\pm \mathrm{SD}$ of the mean of at least three independent experiments. Statistical analysis was performed using one-way ANOVA with NewmanKeuls post hoc test $\left({ }^{*} p<.05\right)$ 


\section{8 | Haemocompatibility analysis}

\subsection{1 | Thrombogenicity}

To evaluate the materials' thrombogenicity, the formation of thrombus on the surface of the membranes was assessed by gravimetry using glass plates as the positive control.
The percentage of thrombogenicity was calculated and expressed as mean $\pm \mathrm{SE}$ of the mean (Figure 8).

Other studies have shown that thrombogenicity is directly related to the value of surface energy presented by materials' surface. ${ }^{[55]}$ More specifically, low surface energy values are reported to be an important factor on the first stage of the coagulation cascade that ends in
$24 h$
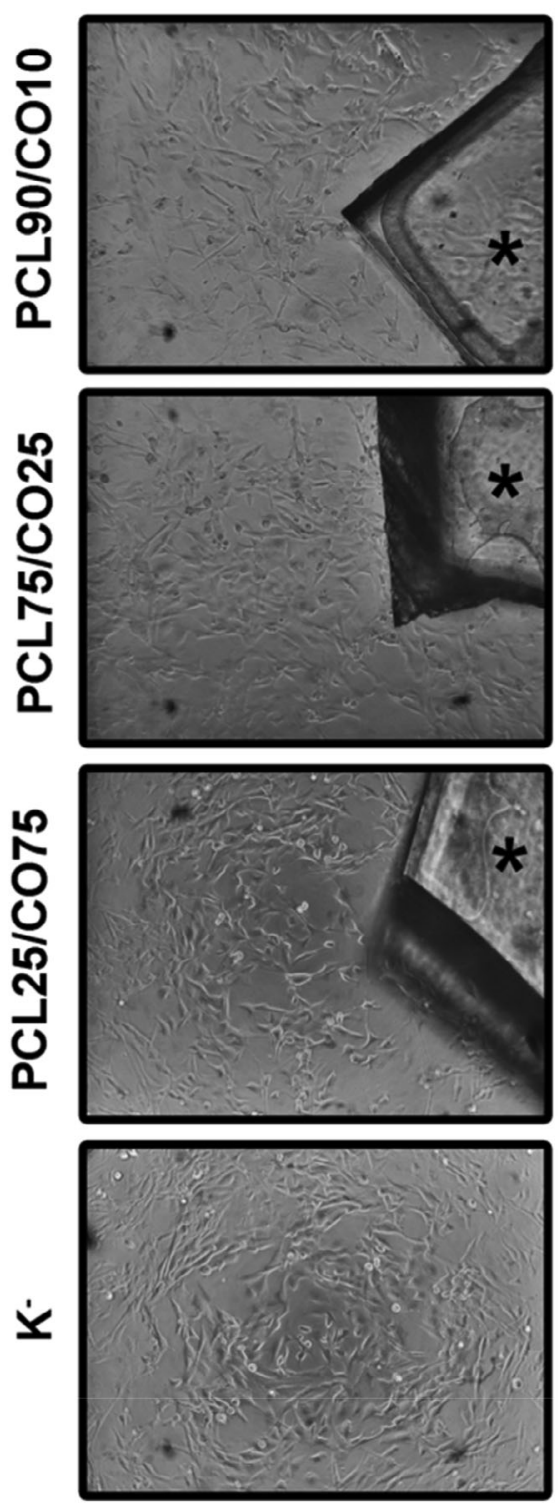

$\pm$

FIG URE 11 Microscopic images of Hfib in contact with the different material blends after $24 \mathrm{hr}$, and $72 \mathrm{hr}$ of incubation at a magnification of $\times 100$
$72 \mathrm{~h}$
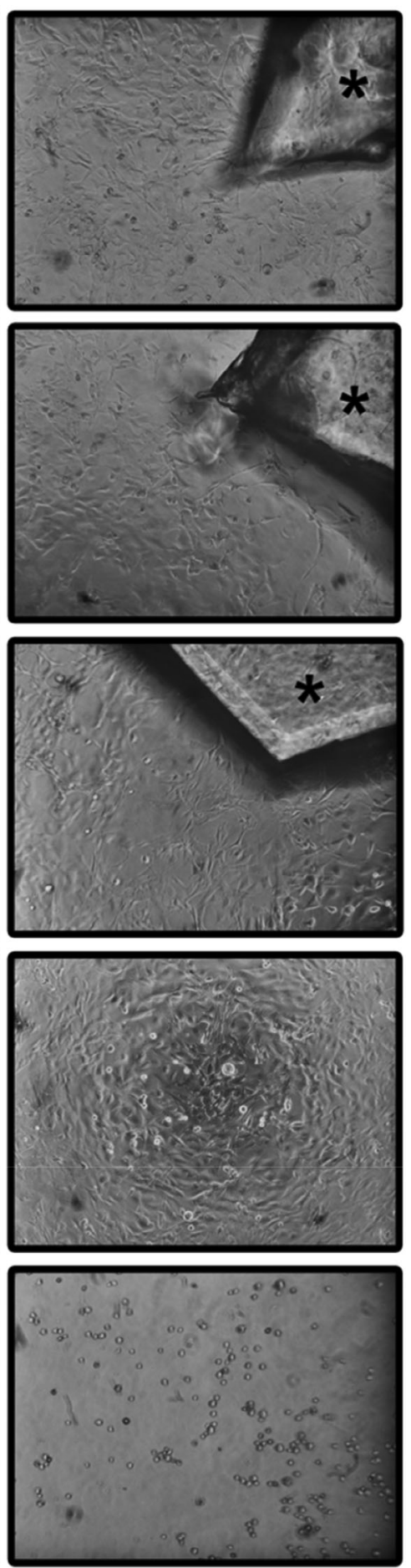
24h

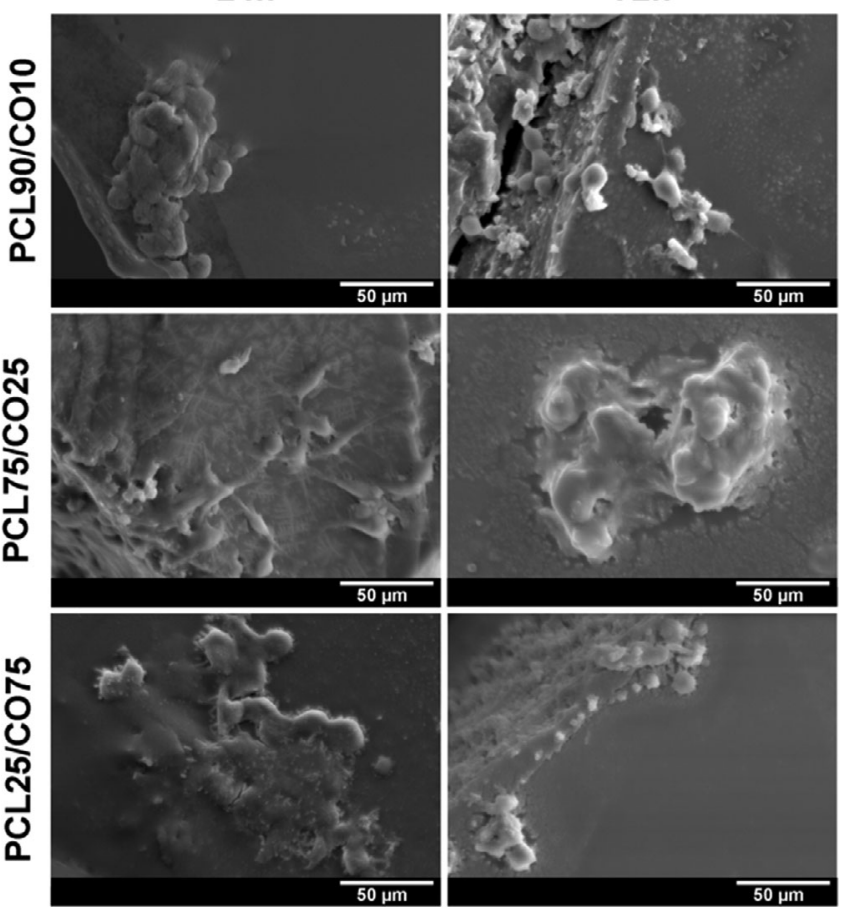

F I G U RE 12 SEM images of Hfib interacting with PCL90/ CO10, PCL75/CO25, and PCL25/CO75 films surface after 24 and $72 \mathrm{hr}$ of incubation

thrombus formation. ${ }^{[56]}$ All the materials used herein presented low surface energy levels and are in fact thrombogenic. However, it was verified an increased thrombogenic activity with the incorporation of $\mathrm{CO}$ in the materials despite the surface energies of the membranes were not significantly different between them. This fact is associated with the lower value of the polar component of the surface energy of the PCL27/CO75 as well as its lower water sorption capacity, since more hydrophobic surfaces induce increased protein adsorption and therefore thrombus formation. ${ }^{[56]}$

\subsection{2 | Haemolytic potential}

The haemolysis index of the membranes prepared from the polymeric blends was evaluated according to ASTM F 756-00 ${ }^{[39]}$ using the cyanmethemoglobin method. Due to its sensitivity, this method allows quantifying levels of plasma hemoglobin that may not be measurable under in vivo conditions. The haemolysis results obtained for all samples during direct and indirect contact with blood are presented in Figure 9.

The haemolytic indexes of all the materials were lower than $2 \%$, being therefore classified as nonhaemolytic according to the ASTM F 756-00. These results indicate that no disruption of the erythrocyte membranes and consequent $\mathrm{Hb}$ release is verified during incubation in the anticoagulated blood during HI assessment. For this reason, materials are considered blood-compatible which is a fundamental feature for the intended biomedical application.

\section{9 | Evaluation of tissue adhesives biocompatibility}

The cytocompatibility of the tissue adhesives was also evaluated through an MTT assay (Figure 10). The results obtained show that after $72 \mathrm{hr}$ of cells being seeded in contact with the produced materials, no acute cytotoxic effect was noticed. The SEM and optical microscopic images presented in Figures 11 and 12 show that, despite of the hydrophobic character and lack of cell-binding motifs on PCL structure, cells were able to adhere and proliferate in contact with the produced materials for at least $72 \mathrm{hr} .{ }^{[31,32]}$ These results also support the future application of the produced materials as tissue adhesives.

\section{4 | CONCLUSIONS}

PCL and CO macromers were prepared by functionalization with IEMA in order to obtain photocrosslinkable materials. This allowed the incorporation of carbon-carbon double bounds in the macromer structure as could be confirmed by ${ }^{1} \mathrm{H}$ NMR analyses. Three different stoichiometric proportions were then tested in the preparation of the PCL/CO polymeric blends. The adhesion capacity tests of the developed blends using gelatine sheets as the substrate demonstrated that the adhesive strength of the materials was extremely high and that their break point was similar to the gelatine maximum force. These macromers were then photocrosslinked with UV irradiation, by using Ir2959 as the photoinitiator and membranes were obtained which were further characterized.

The presence of $\mathrm{CO}$ in the polymeric blends reflected in a lower water sorption capacity and an increased hydrolytic degradation after 6 weeks of incubation. However, thermal properties and surface energies showed to be quite similar among all the materials, regardless their polymeric composition. The same conclusions were achieved when assessing their interaction with blood since all samples showed to be thrombogenic and nonhaemolytic.

In vitro studies showed that, despite the hydrophobic character of the produced materials, cells were able to adhere and proliferate for at least $72 \mathrm{hr}$.

Based on the overall results it one may suggest that polymeric blends based on PCL and $\mathrm{CO}$ present 
interesting features and are good candidates to be used as surgical adhesives.

\section{ACKNOWLEDGMENTS}

This work was supported by the Portuguese Foundation for Science and Technology thought the project FCT Researcher IF/01432/2015. This work was supported by FEDER funds through the POCI - COMPETE 2020 - Operational Program Competitiveness and Internationalization in Axis I - Strengthening research, technological development and innovation (Project POCI-01-0145-FEDER007491) and National Funds by FCT - Foundation for Science and Technology (Project UID/Multi/00709/2013). The funding from CENTRO-01-0145-FEDER-028989 is also acknowledged.

\section{ORCID}

Paula Ferreira (D) https://orcid.org/0000-0003-3393-4427

\section{REFERENCES}

[1] P. Ferreira, J. F. J. Coelho, J. F. Almeida, M. H. Gil, in Biomedical Engineering - Frontiers and Challenges (Ed: R. FazelRezai), IntechOpen, 2011, p. 55.

[2] P. Ferreira, M. H. Gil, P. Alves, in Recent Advances Adhesion Research (Eds: A. McFarland, M. Akins), Nova Science Publishers, New York 2013, p. 59.

[3] The CoStasis Multi-center Collaborative Writing Committee, Surgery 2011, 129, 445.

[4] R. W. Farndale, J. J. Sixma, M. J. Barnes, P. G. De Groot, J. Thromb. Haemost. 2004, 2, 561.

[5] R. Bitton, E. Josef, I. Shimshelashvili, K. Shapira, D. Seliktar, H. Bianco-Peled, Acta Biomater. 2009, 5, 1582.

[6] M. R. Jackson, Am. J. Surg. 2001, 182, 1S.

[7] K. Ono, M. Ishihara, Y. Ozeki, H. Deguchi, M. Sato, Y. Saito, H. Yura, M. Sato, M. Kikuchi, A. Kurita, T. Maehara, Surgery 2001, 130, 844.

[8] N. Mati-Baouche, P. H. Elchinger, H. De Baynast, G. Pierre, C. Delattre, P. Michaud, Eur. Polym. J. 2014, 60, 198.

[9] K. A. Bresnahan, J. M. Howell, J. Wizorek, Ann. Emerg. Med. 1995, 26, 575.

[10] J. L. Rushbrook, G. White, L. Kidger, P. Marsh, T. F. O. Taggart, J. Infect. Prev. 2014, 15, 236.

[11] N. Annabi, K. Yue, A. Tamayol, A. Khademhosseini, Eur. J. Pharm. Biopharm. 2015, 95, 27.

[12] L. Li, H. Zeng, Biotribology 2016, 5, 44.

[13] R. S. Devi, S. A. Kumar, E. Bhuvanes, C. Kavya, Int. J. Adv. Res. Innov. Ideas Educ. 2017, 3, 489.

[14] A. P. Duarte, J. F. Coelho, J. C. Bordado, M. T. Cidade, M. H. Gil, Prog. Polym. Sci. 2012, 37, 1031.

[15] P. Ferreira, R. Pereira, J. F. J. Coelho, A. F. M. Silva, M. H. Gil, Int. J. Biol. Macromol. 2007, 40, 144.

[16] S. Yabe, T. Sato, J. Solid State Chem. 2003, 171, 7.

[17] B. L. Mcfarlin, M. H. Gibson, J. O. Rear, P. Harman, J. Nurse Midwifery 1999, 44, 205.

[18] S. Eiamtrakarn, Y. Itoh, J. Kishimoto, Y. Yoshikawa, N. Shibata, M. Murakami, K. Takada, Biomaterials 2002, 23, 145.
[19] T. E. Lipatova, in Advances in Polymer Science (Ed: K. Dusek), Springer, Berlin Heidelberg 1986, p. 65.

[20] N. Sheikh, H. Mirzadeh, A. A. Katbab, P. Salehian, M. Daliri, S. Amanpour, J. Biomater. Sci. Polym. Ed. 2001, 12, 707.

[21] P. Ferreira, A. F. M. Silva, M. I. Pinto, M. H. Gil, J. Mater. Sci. Mater. Med. 2008, 19, 111.

[22] P. Ferreira, J. F. J. Coelho, R. Pereira, A. F. M. Silva, M. H. Gil, J. Appl. Polym. Sci. 2007, 105, 593.

[23] R. S. Benson, Nucl. Instrum. Methods Phys. Res. B 2002, 191, 752.

[24] J. H. Moon, Y. G. Shul, S. Y. Hong, Y. S. Choi, H. T. Kim, Int. J. Adhes. Adhes. 2005, 25, 301.

[25] J. L. Ifkovits, J. A. Burdick, Tissue Eng. 2007, 13, 2369.

[26] M. Mehdizadeh, J. Yang, Macromol. Biosci. 2013, 13, 271.

[27] P. Ferreira, J. F. J. Coelho, M. H. Gil, Int. J. Pharm. 2008, 352,172

[28] J. Xue, T. Wang, J. Nie, D. Yang, J. Photochem. Photobiol. B Biol. 2013, 119, 31.

[29] B. Azimi, P. Nourpanah, M. Rabiee, S. Arbab, J. Eng. Fibers Fabr. 2014, 9, 74.

[30] A. Rai, S. Senapati, S. K. Saraf, P. Maiti, J. Mater. Chem. B 2016, 4, 5151.

[31] E. Malikmammadov, T. E. Tanir, A. Kiziltay, V. Hasirci, N. Hasirci, J. Biomater. Sci. Polym. Ed. 2018, 29, 863.

[32] M. Abedalwafa, F. Wang, L. Wang, C. Li, Rev. Adv. Mater. Sci. 2013, 34, 123.

[33] H. Kweon, M. K. Yoo, I. K. Park, T. H. Kim, H. C. Lee, H.-S. Lee, J. S. Oh, T. Akaike, C. S. Cho, Biomaterials 2003, 24, 801.

[34] C. G. Williams, A. N. Malik, T. K. Kim, P. N. Manson, J. H. Elisseeff, Biomaterials 2005, 26, 1211.

[35] T. R. Correia, D. R. Figueira, K. D. de Sá, S. P. Miguel, R. G. Fradique, A. G. Mendonça, I. J. Correia, Int. J. Biol. Macromol. 2016, 93, 1432.

[36] J. M. C. Santos, D. S. Marques, P. Alves, T. R. Correia, I. J. Correia, C. M. S. G. Baptista, P. Ferreira, React. Funct. Polym. 2015, 94, 43.

[37] ISO 10993-4:2002, Biological Evaluation of Medical Devices. Part 4: Selection of Tests for Interactions with Blood, 1999.

[38] Y. Imai, Y. Nose, J. Biomed. Mater. Res. 1972, 6, 165.

[39] ASTM F756-00, Standard Practice for Assessment of Hemolytic Properties of Materials, 2000.

[40] M. P. Ribeiro, A. Espiga, D. Silva, P. Baptista, J. Henriques, C. Ferreira, J. C. Silva, J. P. Borges, E. Pires, P. Chaves, I. J. Correia, Wound Repair Regen. 2009, 17, 817.

[41] P. H. Castilho, T. R. Correia, M. T. Pessoa de Amorim, I. C. Escobar, J. A. Queiroz, I. J. Correia, A. M. Morão, J. Appl. Polym. Sci. 2015, 132, 41610.

[42] K. Żółtowska, M. Sobczak, E. Oledzka, Molecules 2015, 20, 2816.

[43] B. W. K. Diehl, Lipid Technol. 2011, 23, 278.

[44] T. M. Cernadas, F. A. M. M. Gonçalves, P. Alves, S. P. Miguel, C. Cabral, I. J. Correia, P. Ferreira, Eur. Polym. J. 2019, 117, 442.

[45] B. D. Ulery, L. S. Nair, C. T. Laurencin, J. Polym. Sci. B Polym. Phys. 2011, 49, 832.

[46] K. R. Kunduru, A. Basu, M. Haim Zada, A. J. Domb, Biomacromolecules 2015, 16, 2572.

[47] P. Alves, R. Cardoso, T. R. Correia, B. P. Antunes, I. J. Correia, P. Ferreira, Colloids Surf. B Biointerfaces 2014, 113, 25. 
[48] S. Venkatraman, R. Gale, Biomaterials 1998, 19, 1119.

[49] S. Agathopoulos, P. Nikolopoulos, J. Biomed. Mater. Res. 1995, 29, 421.

[50] J. Y. Chen, Y. X. Leng, X. B. Tian, L. P. Wang, N. Huang, P. K. Chu, P. Yang, Biomaterials 2002, 23, 2545.

[51] O. Persenaire, M. Alexandre, P. Degée, P. Dubois, Biomacromolecules 2001, 2, 288.

[52] M. Malik, R. Kaur, Adv. Polym. Technol. 2018, 37, 21637.

[53] M. F. Valero, Y. Ortegón, J. Elastomers Plast. 2013, 47, 360.

[54] V. V. Khutoryanskiy, M. G. Cascone, L. Lazzeri, N. Barbani, Z. S. Nurkeeva, G. A. Mun, A. V. Dubolazov, Polym. Int. 2004, 53, 307.

[55] C. Zhao, X. Liu, M. Nomizu, N. Nishi, Biomaterials 2003, 24, 3747.
[56] L. Poussard, F. Burel, J. P. Couvercelle, O. Lesouhaitier, Y. Merhi, M. Tabrizian, C. Bunel, J. Biomater. Sci. Polym. Ed. 2005, 16, 335.

How to cite this article: Cernadas $\mathrm{T}$, Morgado $\mathrm{S}$, Alves P, et al. Preparation of functionalized poly (caprolactone diol)/castor oils blends to be applied as photocrosslinkable tissue adhesives. $J \mathrm{Appl}$ Polym Sci. 2020;e49092. https://doi.org/10.1002/ app.49092 